\title{
Inspeção semiótica no sistema Metahuman Creator: avatares em foco
}

\author{
Renan L. L. de Souza, Cristiano Maciel, Eunice P. dos Santos Nunes \\ ${ }^{1}$ Instituto de Computação - Universidade Federal de Mato Grosso (UFMT) \\ Cuiabá - MT - Brasil \\ re.limasouza00@gmail.com, cmaciel@ufmt.br, eunice@ufmt.br
}

\begin{abstract}
This article addresses the topic of digital immortality and avatars in order to analyze the Metahuman Creator application for the purpose of creating an avatar. Therefore, the objective is to carry out the semiotic inspection in the Metahuman Creator system to evaluate the quality of the metamessage emission between the designer and the user of the system. Thus, the report generated by the evaluation of this system, which used the Semiotic Inspection Method, generated satisfactory results on the use of this system as well as identified some improvements that could be made to facilitate its use, which were socialized in this research.
\end{abstract}

Resumo. O presente artigo aborda o tema sobre imortalidade digital e avatares com o intuito de analisar o aplicativo Metahuman Creator para fins de criação de um avatar. Sendo assim, o objetivo consiste em realizar a inspeção semiótica no sistema Metahuman Creator para avaliar a qualidade da emissão de metamensagem entre o designer e usuário do sistema. Desse modo, o relatório gerado pela avaliação deste sistema, o qual utilizou o Método de Inspeção Semiótica, gerou resultados satisfatórios sobre o uso desse sistema assim como identificou algumas melhorias que poderiam ser realizadas para facilitar seu uso, socializadas nesta pesquisa.

\section{Introdução}

Considerando a grande quantidade de dados que pode ser coletada sobre um indivíduo ao longo de sua vida, é possível perpetuar seus dados por meio de aplicações que fazem uso de técnicas de inteligência artificial, big data, aprendizagem de máquina e redes neurais [Galvão et al. 2017]. O resultado disso é a possibilidade da imortalidade digital [Galvão et al. 2021], pois o sujeito imerso no ciberespaço pode ser imortal, dado que sua representação digital em forma de avatar ou corpo virtual, que é inorgânico, é incapaz de cessar.

A imortalidade digital, segundo Gordon Bell e Jim Gray (2000) é definida como "imortalidade ordinária, é uma continuação da fama duradoura para um fim de uma experiência interminável e aprendizado com o outro, sendo algo mais próximo da vida infinita." [Bell and Gray 2000]. Sendo assim, a natureza de imortalidade digital reside na preservação da identidade do usuário, mantendo-a viva mesmo após o falecimento do indivíduo.

Uma maneira de imortalizar indivíduos é por meio de avatares [Silva et al. 2021]. O termo avatar provém de origem religiosa o qual retrata a materialização de uma divindade na terra. Dessa forma, Neal Stephenson (1992) apropriou deste conceito em seu 
livro Snow Crash para retratar os avatares como pessoas imersas em um ambiente virtual. Com o aplicativo Metahuman, por exemplo, é possível criar um avatar personalizado, de modo que represente o usuário no meio cibernético. Esse tipo de avatar pode ser útil, por representar de uma forma realística o usuário sem exceder ou desfigurar as características humanas, o que motivou esta pesquisa. Cabe salientar que a pesquisa faz parte dos estudos do Projeto DAVI - Dados Além da Vida [DAVI 2021].

Todavia, como se dá a comunicação do Metahuman, com seus usuários, durante sua utilização? Com vistas a responder este problema, o objetivo deste artigo é apresentar a condução de uma inspeção semiótica, que consiste em avaliar a qualidade da emissão de metamensagem entre o designer e usuário, do sistema Metahuman.

Para tal, é usado o Método de Inspeção Semiótica (MIS) [de Souza and Leitão 2009], aplicado no sistema Metahuman por um especialista em Interação HumanoComputador (IHC). A utilização do MIS irá permitir responder a pergunta mencionada anteriormente, pois as etapas presentes na inspeção abordam a forma como o sistema é organizado e utilizado. Com base no relatório gerado a partir desta avaliação, de cunho qualitativo, foi gerado este artigo.

\section{Referencial Teórico}

Para melhor contextualizar os temas deste artigo, alguns referenciais basilares da pesquisa são apresentados nesta seção.

\subsection{Avatar}

O termo avatar é antigo e advém de origem religiosa, nasceu no sânscrito avatara que significa "descida de uma divindade do paraíso a terra" retratando cada uma das formas humanas ou animais assumidas pelo deus hindu Vixnu ao visitar a humanidade [Rodrigues 2021]. Avatar era a materialização de uma força espiritual. Este conceito foi popularizado no mundo digital por meio do livro Snow Crash, escrito por Neal Stephenson (1992), no qual retrata um Ambiente Virtual Tridimensional (AV 3D) em rede no qual os usuários poderiam adotar personalidades, viver outras vidas ou apenas estender sua existência [Araujo 2015].

Dessa forma, o avatar foi sendo introduzido em vários jogos, permitindo retratar a imagem do usuário em forma de um personagem o qual o representaria no jogo. De acordo com Daniel Kromand (2007) dentro do mundo imersivo dos jogos existem dois tipos de avatares: fechado e aberto. O primeiro se refere aos avatares que já possuem sua personalidade definida desde o começo do jogo como, por exemplo, Mario e Lara Croft. No entanto, o segundo retrata avatares que são desprovidos de personalidades, pois elas são construídas conforme as escolhas do jogador. Temos o jogo SecondLife e World of Warcraft que representam este cenário.

Diante dos avatares abertos, é possível alterar e modificar o seu avatar da maneira que desejar, não precisando necessariamente representar fielmente sua forma e aparência física da realidade com o mundo virtual o qual está inserido. Sendo assim, tal liberdade permite que seja possível viver vários personagens com características e personalidades diferentes. O autor Neal Stephenson (1992) em seu livro Snow Crash reafirma esta liberdade de escolha ao dizer: 
As pessoas são pedaços de software chamados avatares. Eles são os corpos audiovisuais que as pessoas utilizam para se comunicarem umas com as outras no metaverso. [...]. Seu avatar pode ter a aparência que você quiser, limitada somente por seu equipamento [Stephenson 1992].

Há que se considerar ainda que, como na perspectiva de Coleman (2012), o conceito de avatar não se restringe apenas às figuras animadas que povoam as telas digitais, mas o agrupamento de imagens, textos e multimídia que constituem nossas identidades em mundos virtuais e na forma de e-mail, chat-online, vídeo e outros artefatos digitais. Ou seja, uma foto em uma rede social, um ícone gráfico em um fórum ou chat e o corpo virtual de alguém imerso em um ambiente virtual, também abrangem o conceito de avatar.

Mediante o exposto, percebe-se que o avatar possui uma parte sensível que deve ser analisada cuidadosamente. Tal parte é composta por sua aparência, pois existe o termo "vale da estranheza". Tal termo é uma hipótese proposta por Mori (1970) a qual sugere que existe uma tendência geral dos humanos em gostar de elementos que representam feições humanas. Porém, quando há um nível exagerado de antropomorfismo desproporcional aos aspectos humanos, evoca reações negativas. Quando as representações são vistas como muito parecido com humano, mas ainda não humano, elas são vistas como estranhas e desconfortáveis.

O avatar é, portanto, uma representação do usuário no meio cibernético, o qual permite ele interagir no ambiente e ter sua forma exposta neste vasto espaço virtual. Há aplicativos como o Metahuman Creator, apresentado na próxima seção, que viabiliza a criação de avatares customizados. Sendo o avatar uma "instanciação"do usuário, é possível utilizar deste meio para imortalizá-lo visto que o avatar pode permanecer no meio cibérnetico mesmo após a morte do seu usuário. Deste modo, o usuário é imortalizado.

\subsection{Metahuman Creator}

O Metahuman Creator (2021) é um aplicativo de nuvem elaborado pela Epic Games com o objetivo de criar humanos digitais ultra realistas. O aplicativo dispõe de um menu de criação que possui funções diferentes para poder moldar um personagem. Tais funções permitem editar desde características básicas como cabeça, olhos e boca até detalhadas como o formato dos dentes, simetria e rugas na face. Com isso, permite que o personagem tenha um traço único e uma alta similaridade a um ser humano. Após concluir a edição do personagem, é possível baixar a sua criação via Quixel Bridge que é um programa utilizado para importar e exportar projetos 3D. Depois de transferir sua criação ao Quixel Bridge é necessário exportar para algum motor de jogos para dar vida ao seu personagem como, por exemplo, Unreal Engine. Nele é possível adicionar movimentos e cenários ao seu personagem que pode ser usado em jogos e outros ambientes virtuais.

Em entrevista com o vice-presidente de tecnologia da Epic Games, Vlad Mastilovi 'c [Travers 2021], ele apresenta sua visão sobre seu aplicativo: "Eu vejo os humanos digitais como um reflexo de nós mesmos e, como tal, eles têm uma ampla aplicação no espaço de jogos". Em seguida, Vlad Mastilovi 'c propõe outras utilidades e visões futuras para seu aplicativo, como utilizar os humanos digitais para aprender por meio deles, explorando sua anatomia, formas de se movimentar melhor em práticas esportivas ou aprender a dançar. 


\subsection{Método de Inspeção Semiótica}

Com vistas a realizar o propósito do artigo, a metodologia consiste em uma pesquisa aplicada com abordagem qualitativa que se utilizou de pesquisa bibliográfica e do Método de Inspeção Semiótica (MIS). O MIS foi fundamentado pela engenharia semiótica. Seu objetivo consiste em identificar os possíveis problemas na qualidade da emissão de metamensagem, que são mensagens que instruem como interpretar o sistema, entre o designer e usuário [de Souza and Leitão 2009]. A aplicação do MIS é feita por um avaliador e não necessita da participação de usuários.

A engenharia semiótica classifica os signos codificados na interface em três tipos: estático, dinâmico e metalinguístico. Esta classificação se encarrega de orientar o trabalho do avaliador durante a inspeção semiótica. Durante a inspeção de cada tipo de signo, o avaliador deve analisar a interface, incluindo a documentação disponível ao usuário. Posteriormente, o avaliador precisa identificar os signos daquele tipo codificado no sistema com o objetivo de reconstruir a metamensagem do designer [Barbosa and da Silva 2010]. Sendo assim, o avaliador tem três versões da metamensagem reconstruída, uma para cada tipo de signo. Sucessivamente, o avaliador compara as três metamensagens reconstruídas, e finalmente faz um parecer sobre a comunicabilidade do sistema interativo.

Tabela 1. Atividades do Método de Inspeção Semiótica

\begin{tabular}{|c|c|}
\hline \multicolumn{2}{|r|}{ inspeção semiótica } \\
\hline atividade & tarefa \\
\hline Preparaçáo & $\begin{array}{l}\text { " identificar os perfis de usuários } \\
\text { " identificar os objetivos apoiados pelo sistema } \\
\text { " definir as partes da interface que seráo avaliadas } \\
\text { " escrever cenários de interaçáo para guiar a avaliaçáo }\end{array}$ \\
\hline $\begin{array}{l}\text { Coleta de } \\
\text { dados }\end{array}$ & $\begin{array}{l}\text { " inspecionar a interface simulando a interaçáo descrita pelo cenário de } \\
\text { interaçáo }\end{array}$ \\
\hline Interpretaçăo & $\begin{array}{l}\text { " analisar os signos metalinguísticos e reconstruir a metamensagem } \\
\text { correspondente } \\
\text { " analisar os signos estáticos e reconstruir a metamensagem correspondente } \\
\text { " analisar os signos dinâmicos e reconstruir a metamensagem correspondente }\end{array}$ \\
\hline $\begin{array}{l}\text { Consolidaçáo } \\
\text { dos resultados }\end{array}$ & $\begin{array}{l}\text { " contrastar e comparar as metamensagens reconstruídas nas análises de } \\
\text { cada tipo de signo } \\
\text { " julgar os problemas de comunicabilidade encontrados }\end{array}$ \\
\hline $\begin{array}{l}\text { Relato dos } \\
\text { resultados }\end{array}$ & $\begin{array}{l}\text { " relatar a avaliaçáo da comunicabilidade da soluçáo de IHC, sob o ponto de } \\
\text { vista do emissor da metamensagem }\end{array}$ \\
\hline
\end{tabular}

A Tabela 1 explicita as atividades do Método de Inspeção Semiótica utilizadas no sistema do Metahuman Creator. A avaliação é dividida em cinco etapas. Na $1^{\mathrm{a}}$ etapa o avaliador prepara seu ambiente identificando o perfil dos usuários que utilizam o sistema que será inspecionado e escreve cenários de interação ao das interfaces escolhidas para avaliação. Logo após, vem a $2^{\mathrm{a}}$ e $3^{\mathrm{a}}$ etapas, quando o inspetor fará uma análise dos signos que compõem a interface do sistema simulando a interação de usuários de acordo com os cenários descritos da $1^{\text {a }}$ etapa, com o objetivo de reconstruir a metamensagem. $\mathrm{Na} 4^{\mathrm{a}}$ etapa, é feita uma comparação das metamensagens reconstruídas apresentando as falhas encontradas na comunicabilidade, em seguida, na $5^{\text {a }}$ etapa, o avaliador descreve sob a perspectiva de emissor da metamensagem a solução de IHC para as falhas encontradas. Com base nessas atividades, os autores realizaram a inspeção. 


\subsubsection{Perfil e Objetivo}

O perfil dos usuários que entram em contato com o sistema é de pessoas com conhecimentos básicos de informática e/ou que já operaram outros aplicativos de criação de avatares digitais, sendo assim, capacitadas para realizar o objetivo do sistema que é criar seu próprio avatar.

\subsubsection{Cenário}

Um usuário comum que é familiarizado com o conceito de avatar, compreende o básico de tecnologia e vive submerso no metaverso conhecido popularmente como a internet, deseja criar seu proprio avatar para representar ele digitalmente com o intuito de interagir com os demais na internet, utilizando o aplicativo Metahuman. Sendo assim, ele acessa o aplicativo pelo site e na página inicial realiza seu login. Após isso, ele obtém acesso a todos os itens, ferramentas e formas para criar seu avatar. Desta forma, o usuário vai construindo seu avatar até representar ele da forma como quer. Depois de terminar seu avatar, ele é salvo.

\section{Resultados}

Nesta seção, serão apresentados os resultados da análise do MIS no Metahuman.

\subsection{Comparação entre as três metamensagens}

A partir dos exemplos anteriores foi possível constatar que as metamensagens reconstruídas dos signos metalinguísticos e estáticos indicam que o usuário privilegia a eficiência e praticidade, permitindo o acesso a inúmeras funções diferentes, divididas de forma clara e objetiva, quando o usuário entra na tela de edição do avatar. Para tal efeito, o usuário é guiado pelas legendas que auxiliem identificar a função de cada item e é possível visualizar as alterações no próprio avatar que vai atualizando conforme as escolhas. Desta forma, é perceptível a intenção de facilitar o manuseio e modificação do avatar sem ter dificuldades com ferramentas complexas e incompreensíveis.

Já na metamensagem reconstruída a partir dos signos dinâmicos, o designer parece considerar a importância da objetividade e simplicidade, assim como diferentes formas de manipular as estruturas fenotípicas do avatar. Porém, o usuário passa mais tempo nestas ferramentas de esculpir por apresentar várias formas e meios de alterar a face do personagem. Dessa forma, é previsto um considerável tempo gasto nesta seção para o usuário compreender as alterações e realizar as manipulações conforme deseja. Este tipo de inconsistência pode resultar em um maior tempo na compreensão da ferramenta dependendo do conhecimento e facilidade do usuário. Sendo assim, pode causar um impacto negativo na experiência do usuário, tendo resultados desagradáveis.

A seguir será descrita metamensagem unificada após a análise das metamensagens reconstruídas.

"Eu acredito que você tem um conhecimento básico sobre avatares, visto que conhece suas características e já viu em outros ambientes como jogos, aplicativos e programas. E dado que pretende criar seu próprio avatar, irá usar as ferramentas do programa 
para moldar da forma que deseja seu avatar. Como você já é familiarizado com avatares e já criou ou pelo menos visualizou um em outras plataformas, como por exemplo algum jogo ou site, você deseja que o programa seja fácil de compreender e rápido para construir seu avatar sem ter que lidar com programas complexos.

Para garantir isso, eu dividi a estrutura do corpo em três partes, sendo cabeça, cabelo e corpo. E dentro delas organizei as características cabíveis a cada parte para você poder encontrar e manipular facilmente as partes desejadas. Dessa forma, lendo os itens você irá conseguir alterar e definir as características do seu avatar facilmente.

Consequentemente, deseja também alterar propriedades mais específicas como tamanho da testa, lábios e nariz. Para atingir tal efeito, criei as opções de esculpir para poder aprofundar e variar o quanto quiser seu avatar e visualizar as modificações. Sendo assim as opções que você terá serão ilimitadas."

\subsection{Discussões}

O uso do Método de Inspeção Semiótica no aplicativo Metahuman permitiu explorar a forma como ele funciona, discorrendo passo a passo nas etapas que o usuário deve seguir para desenvolver e finalizar seu avatar. Ficou evidente como as várias ferramentas e interface do Metahuman atuam e proporcionam ao usuário controle total sobre seu avatar, permitindo dessa forma, que ele o altere e/ou modifique da forma como deseja.

Entretanto, foram encontradas algumas complicações que podem dificultar a utilização do aplicativo. Primeiramente, o aplicativo demanda um computador com placa de vídeo razoável para conseguir renderizar o avatar sem apresentar lentidão e erro. Além disso, como existem diversos itens e ferramentas para alterar o avatar, pode ser que o usuário demore um tempo significativo para encontrar determinado item e ajustar de sua maneira. Há também algumas limitações sobre a escolha de roupa, de modo que são disponibilizadas poucas opções para serem utilizadas no avatar.

\section{Considerações Finais}

O Método de Inspeção Semiótica (MIS) evidenciou que o Metahuman é um aplicativo propício para a criação de um avatar. Tal justificativa se baseia nas inúmeras utilidades e benefícios que o aplicativo apresenta. Dessa forma, a partir da análise do Metahuman utilizando o MIS, foi possível responder ao problema proposto na introdução.

Devido às limitações da pesquisa foi utilizado apenas um método de avaliação da interação. Entretanto, há como explorar outros métodos para analisar o Metahuman como o Percurso Cognitivo, que permite avaliar a facilidade de aprendizado de um sistema interativo e o método de Avaliação Heurística que busca identificar falhas de usabilidade durante um processo de design interativo. Contudo, pode ocorrer do próprio Metahuman evoluir e proporcionar novas ferramentas e meios para o usuário criar seu avatar.

Com vistas a futuros estudos sobre imortalidade, é relevante abordar outros aplicativos que visam criar avatar do usuário, como forma de representá-lo após sua morte. Ainda, busca-se investigar sobre o comportamento do avatar, para o qual, pretende-se iniciar com a montagem da história de vida de uma pessoa a ser imortalizada. Visto que a representação digital do usuário constitui uma parte de sua identidade, é substancial à imortalidade digital. 


\section{Agradecimentos}

Os autores agradecem ao Conselho Nacional de Desenvolvimento Científico e Tecnológico - CNPq e a Pró-Reitoria de Pesquisa da Universidade Federal de Mato Grosso.

\section{Referências}

Araujo, W. S. (2015). Avatares - da sua natureza mítica aos processos de avatarização orientados por procedimentos interativos, discursivos e literários: Diálogos. Ipotesi, 19:1,18.

Barbosa, S. D. J. and da Silva, B. S. (2010). Interação humano-computador. Elsevier.

Bell, G. and Gray, J. (2000). Digital immortality. Microsoft Research.

Coleman, B. (2012). Hello avatar: rise of the networked generation. MIT.

DAVI (2021). Projeto "dados além da vida". Disponível em: https://lavi.ic. ufmt.br/davi/,.

de Souza, C. S. and Leitão, C. F. (2009). Semiotic engineering methods for scientific research in hci. Morgan Claypool.

Galvão, V. F., Maciel, C., Pereira, V. C., Garcia, A. C. B., Pereira, R., and Viterbo, J. (2021). Posthumous data at stake: An overview of digital immortality issues. IHC'21, New York, NY, USA. Association for Computing Machinery.

Galvão, V. F., Maciel, C., Garcia, A. C. B., and Viterbo, J. (2017). Life beyond the physical body: The possibilities of digital immortality. In 2017 XLIII Latin American Computer Conference (CLEI), pages 1-10. IEEE.

Kromand, D. (2007). Avatar categorization. DIGRA.

Metahuman (2021). Metahuman creator. Disponível em: https://metahuman. unrealengine.com/. Acesso em: 17 de agosto de 2021.

Mori, M. (1970). The uncanney valley. Energy.

Rodrigues, S. (2021). Avatar: a palavra que desceu do céu à tela. Disponível em: https://veja.abril.com.br/blog/sobre-palavras/ avatar-a-palavra-que-desceu-do-ceu-a-tela/. Acesso em: 18 de agosto de 2021.

Silva, P., Trevisan, D., and Maciel, C. (2021). A recriação da vida em chatbot e avatares com o uso de dados póstumos. In Anais do XII Workshop sobre Aspectos da Interação Humano-Computador para a Web Social, pages 17-24, Porto Alegre, RS, Brasil. SBC.

Stephenson, N. (1992). Snow crash. Bantam Books.

Travers, C. (2021). Vlad mastilovic, vp of digital humans technology at epic games, tells us what's next.

Disponível em: https://www.virtualhumans.org/article/ vlad-mastilovic-vp-of-digital-humans-technology-at-epic-V games-tells-us-whats-next. Acesso em: 13 de julho de 2021. 